\title{
脳動脈瘤と脳動静脈奇形合併例の治療
}

\author{
塩川 芳昭, 青木 信彦, 久保田勝 \\ 水谷弘, 斉藤勇, 高倉 公朋*
}

\section{Treatment of Cases with Coexisting Intracranial Aneurysms and Arterio- venous Malformations}

Yoshiaki Shiokawa, M.D., Nobuhiko Aoki, M.D., Masaru Kubota, M.D.,

Hirosi Mizutani, M.D., Isamu Saito, M.D., and Kintomo Takakura, M.D.*

Department of Neurosurgery, Tokyo Metropolitan Fuchu Hospital, and

* Department of Neurosurgery, University of Tokyo, Tokyo, Japan

\begin{abstract}
Summary : Cerebral aneurysms associated with arteriovenous malformation (AVM) have often been reported with special reference to the hemodynamic effect of aneurysm formation. In this paper, we surveyed 15 cases with such combinations and discussed the etiologic aspects and suitable therapeutic plans.

The mean age of our patients was older than that of patients with AVM's alone. This suggests that the duration of the hemodynamic effect was important in the formation of aneurysms associated with AVM's. Seventy-two percent of the aneurysms were located on the arteries hemodynamically related to the AVM. When the size of the nidus was larger, aneurysms tended to be located more peripherally on the feeding arteries close to the nidus.

Though both AVM's and aneurysms cause hemorrhagic cerebrovascular diseases, their natural histories differ, especially in the rate and timing of rebleeding. It is important to determine which lesion is responsible for the bleeding. When there is subarachnoid hemorrhage (SAH) but no intracerebral $(\mathrm{ICH})$ or intraventricular hemorrhage (IVH) are shown on the CT scan, the bleeding source will be a ruptured aneurysm. On the other hand, ICH or IVH with or without SAH is mainly due to AVM rupture.

In treatment of cases where aneurysms are associated with an AVM, both lesions should be operated on simultaneously, and if this is impossible, the responsible lesion should be operated on first. In cases with aneurysm rupture, considering its high risk of rebleeding in the acute stage, the aneurysm should be clipped as soon as possible. Even if the aneurysm is not ruptured but is located on an artery where aneurysms usually develop, such aneurysms should also be operated on because of the high risk of bleeding.
\end{abstract}

\author{
Key words : \\ - arteriovenous \\ malformation \\ - aneurysm \\ - computed tomography
}




\section{はじめに}

脳動脈瘤と脳動静脈奇形 (以下 AVM)の合併はしばしば 報告されているが, 臨床的には(1)出血源の同定, (2)治療法 とその順序, (3)非責任病巣に対する治療方針など論議すべ き問題を含んでいる.この点についてわれわれは, 自験15 症例の CT, 血管撮影, 手術および剖検所見を retrospectiveに検討した。

\section{対象および結果}

対象は Table 1 に示した二施設の AVM 398例中動脈瘤 を合併した15例，22動脈瘤である．施設の性格が異なるた め単純にその頻度を算出することには無理があるが，府中 病院について全動脈瘤の $1 \%$, 全 AVM の $7 \%$ に両者の 合併例がみられたのは，おおむね諸家の報告に一致する.

自験例の内訳をTable 2 に一覧した。性別は男 8 例，女 7 例とほぼ同数であり, 年齢は15～67歳 (平均44.6歳) と, 一般の AVM の年齢よりやや高かった。発症形式はCT 所見を考慮して細分し，クモ膜下腔のみに高吸収域を認め

Table 1 Presented cases

\begin{tabular}{lccc}
\hline & aneurysm & AVM & aneurysm+AVM \\
\hline $\begin{array}{l}\text { TOKYO UNIV. } \\
\text { 1968 1985 }\end{array}$ & 668 & 322 & 10 \\
$\begin{array}{l}\text { FUCHU HOSP. } \\
1976 \sim 1985\end{array}$ & 560 & 76 & 5 \\
\hline & & & \\
\hline
\end{tabular}

るものを $\mathrm{SAH}$, 脳内出血を $\mathrm{ICH}$, 脳室内出血を IVH と して表中に示した. 初診時 CT が行われていないが突発す る強い頭痛の history から頭蓋内出血と思われるものは headache とした. 出血以外で発症したものは, 痤攣発作 2 例, 虚血 1 例, 耳鳴 1 例であった，出血例のうち手術 • 剖検時に出血源を確定しえた 7 例 (AVM 2 例，動脈瘤 5 例)を表中太字で示すと, 動脈瘤からの出血によるものは CT 上 SAH が主体であるのに対し，AVM からの出血に よるものは CT 上 SAH に加えて ICH や IVH を伴う傾向 がみられた。具体例として AVM からの出血が手術時に 確認された症例 6 の初診時 CT を示す (Fig. 1). 本症例は 左小脳半球に nidus があり, feeder である上小脳動脈瘤末 梢に 2 個の動脈瘤を伴っていた. 発症時の CTでは広範に $\mathrm{SAH}$ がみられるが，特に小脳脚から第 4 脳室にかけての 脳室および脳実質内に高吸収域が認められ, 動脈瘤破裂に よる一般のクモ膜下出血の CT 像とは異なった所見である. 一方, 動脈瘤が出血源であった症例 $8,11,13$ の初診時 CT はいずれもクモ膜下腔のみに高吸収域を認める（後述の primary SAH)ものであった.

AVM の nidus の大きさは最大計 $3 \mathrm{~cm}$ 以下の小さなも のが 9 例と多く, また nidus の局在であるが，後頭葉およ び小脳半球の vertebro-basilar 系に 7 例が位置していた.

AVM と動脈瘤の位置関係を検討するため動脈瘤の発生 部位をPerret ら ${ }^{1)}$ に準じて以下の 3 群に分けた。すなわち A 群;incidental すなわち feeder と無関係に通常の動脈瘤 好発部に生じたもの，B群;feeder 上で通常の動脈瘤好発 部に生じたもの，C群;feeder 上の末梢部で動脈瘤をみる ことが少ない unusual な部位に生じたものとし, nidusの

Table 2 Summary of the presented cases (1)

\begin{tabular}{rllllll}
\hline & Age, Sex & \multicolumn{1}{c}{ Onset } & Location of AVM & Size of AVM & Location of aneurysm \\
\hline 1. & 15 & $\mathrm{~F}$ & IVH & basal ggl. & small & lenticulostriate \\
2. & 24 & $\mathrm{~F}$ & IVH & basal ggl. & large & post-chor \\
3. & 35 & $\mathrm{M}$ & epilepsy & temporal & small & distal-PCA \\
4. & 35 & $\mathrm{M}$ & ischemia & frontal & large & ICcav, IC ant-chor \\
5. & 40 & $\mathrm{M}$ & Headache & cerebellar & medium & distal-PICA \\
6. & 41 & $\mathrm{M}$ & SAH, ICH, IVH & CEREBELLAR & SMALL & distal-SCA 2 \\
7. & 42 & $\mathrm{M}$ & Headache & temporal & medium & ICPC, MC \\
8. & 42 & $\mathrm{~F}$ & SAH & dural & small & MC \\
9. & 47 & $\mathrm{~F}$ & Headache & CEREBELLAR & SMALL & distal-PICA \\
10. & 47 & $\mathrm{M}$ & epilepsy & cerebellar & medium & distal-PICA \\
11. & 50 & $\mathrm{~F}$ & SAH & occipital & small & A-COM \\
12. & 56 & $\mathrm{M}$ & Headache & temporal & small & BASILAR, PCA $\times 2$ \\
13. & 61 & $\mathrm{~F}$ & SAH & temporal & small & A-COM \\
14. & 67 & $\mathrm{~F}$ & tinnitus & dural & small & ICPC, IC ant-chor \\
15. & 67 & $\mathrm{M}$ & Headache & occipital & medium & ICPC, DISTAL-PCA \\
\hline
\end{tabular}

Gothic type......verified ruptured lesions

size of AVM.....small $<3 \mathrm{~cm}$, medium; $3 \sim 6 \mathrm{~cm}$ large $>6 \mathrm{~cm}$

Headache......sudden onset severe headache 


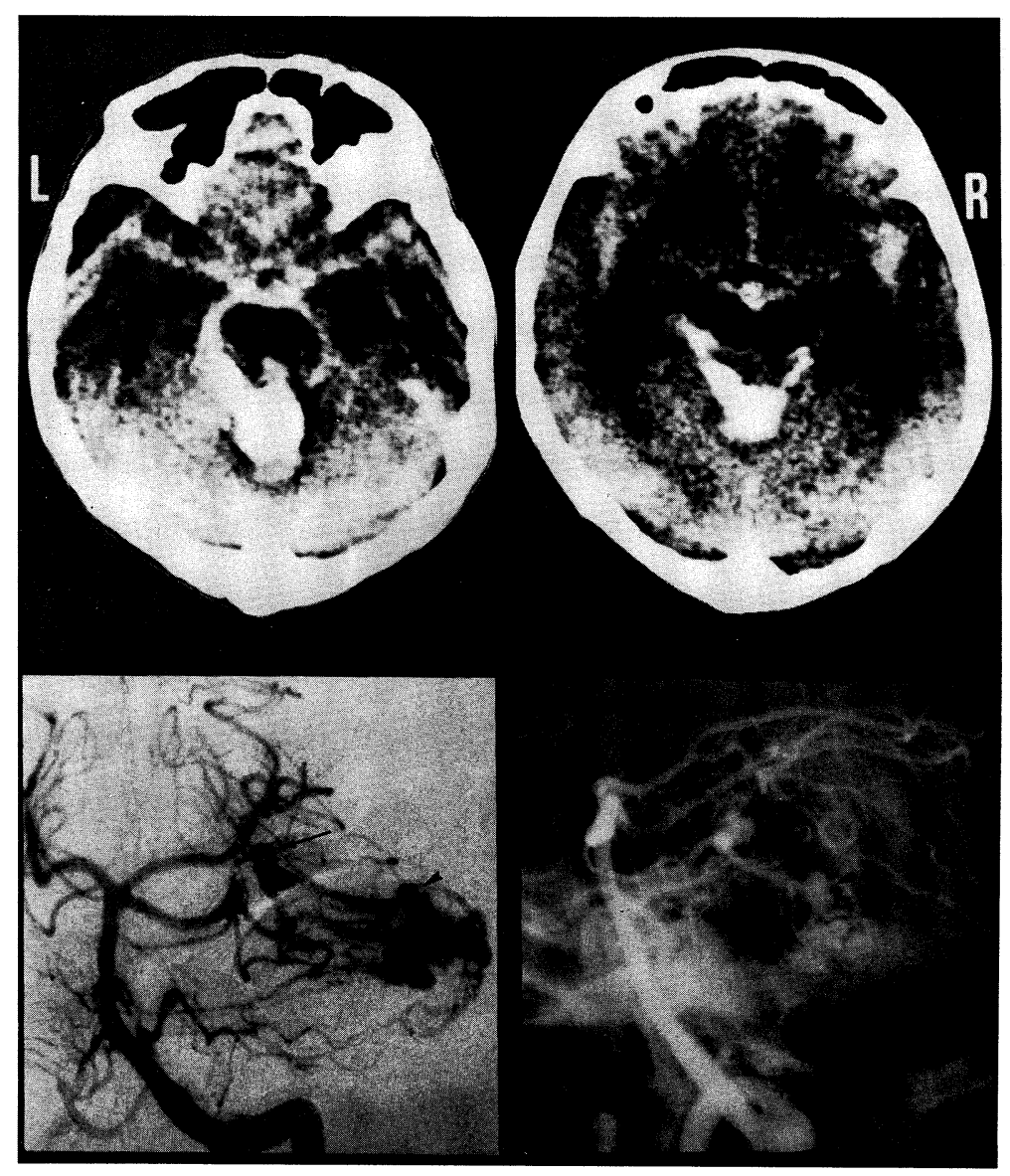

Fig. 1 Case 6. Initial CT scan and left VAG.

Table 3 Size of AVM and location of aneurysms

\begin{tabular}{rcccc}
\hline $\begin{array}{c}\text { Size of } \\
\text { AVM }\end{array}$ & $\begin{array}{c}\text { Number } \\
\text { of cases }\end{array}$ & $\begin{array}{c}\text { Incidental } \\
(\mathrm{A})\end{array}$ & $\begin{array}{c}\text { feeder } \\
\text { (proximal) } \\
\text { (B) }\end{array}$ & $\begin{array}{c}\text { feeder } \\
(\text { distal) } \\
(\mathrm{C})\end{array}$ \\
\hline$<3 \mathrm{~cm}$ & 9 & $5(3)$ & 2 & 6 \\
$3 \sim 6 \mathrm{~cm}$ & 4 & 1 & $2(1)$ & $3(1)$ \\
$>6 \mathrm{~cm}$ & 2 & 0 & 2 & 1 \\
\hline & 15 & 6 & 6 & 10 \\
\hline
\end{tabular}

( )......verified ruptured aneurysm

大きさと比較した (Table 3)。動脈瘤はA 群 6 個，B群 6 個， C 群10個と feede 上で, nidus 近傍に多くみられ, この傾 向はAVM が大きいものほど強かった。一般にAVMの nidus の大きさはその血流を反映するといわれているが2), 前述のごとくわれわれのシリーズでは nidus の小さなもの が多かった点はAVM と動脈瘤の合併する機序を考える と逆説的であるかのごとき印象を受ける. しかし多くの動 脈瘤が feeder 上のしかも nidus 近傍に位置していたのは, やはりこれらの動脈瘤の発生に hemodynamic effect が関 与している証拠ということができよう。確認された破裂動

120 脳卒中の外科 $16: 1988$
脈瘤 5 個の内訳は $\mathrm{A}$ 群 3 個, B 群 1 個, C 群 1 個と, feeder と無関係な通常の動脈瘤好発部に発生したものに多 かった点は，治療方針をたてるうえで重要である，手術時 期およびその内容を各症例毎に検討し Table 4 に一覧した。 摘出術, 塞栓術, クリッピングなどの外科的処置は11例に 計13回行われており，これらの内訳と処置された病巣を表 中太字で示した。両者を同時に処置しえた 5 例 (症例 3,5 , $6,9,10)$ の動脈瘤はすべて feeder 上の末梢で, nidus 近 傍に位置していた. AVM 摘出後二期的に動脈瘤を処置し た 2 例 (症例 7,14$)$ と, 動脈瘤のみ処置した 3 例 (症例 4 , 8,13) はみな通常の動脈瘤好発部に発生したものである. AVM のみ処置したところ 1 か月後に動脈瘤が自然消失し た 1 例 (症例 1 ) と, AVM に手術適応がないため経過を観 察していたところ動脈瘤のみ自然消失した 1 例 (症例 2 )の 計 2 例に動脈瘤の自然消失をみており, これらはいずれも feeder 上の末梢部に位置しており，また若年者であった。 手術に至らず出血死し剖検を行った 2 例 (症例 11,15$)$ はと もに動脈瘤からの出血であり, 初回出血後24時間以内に動 脈瘤からの再出血を起こし死亡したものである. 
Table 4 Summary of the presented cases (2)

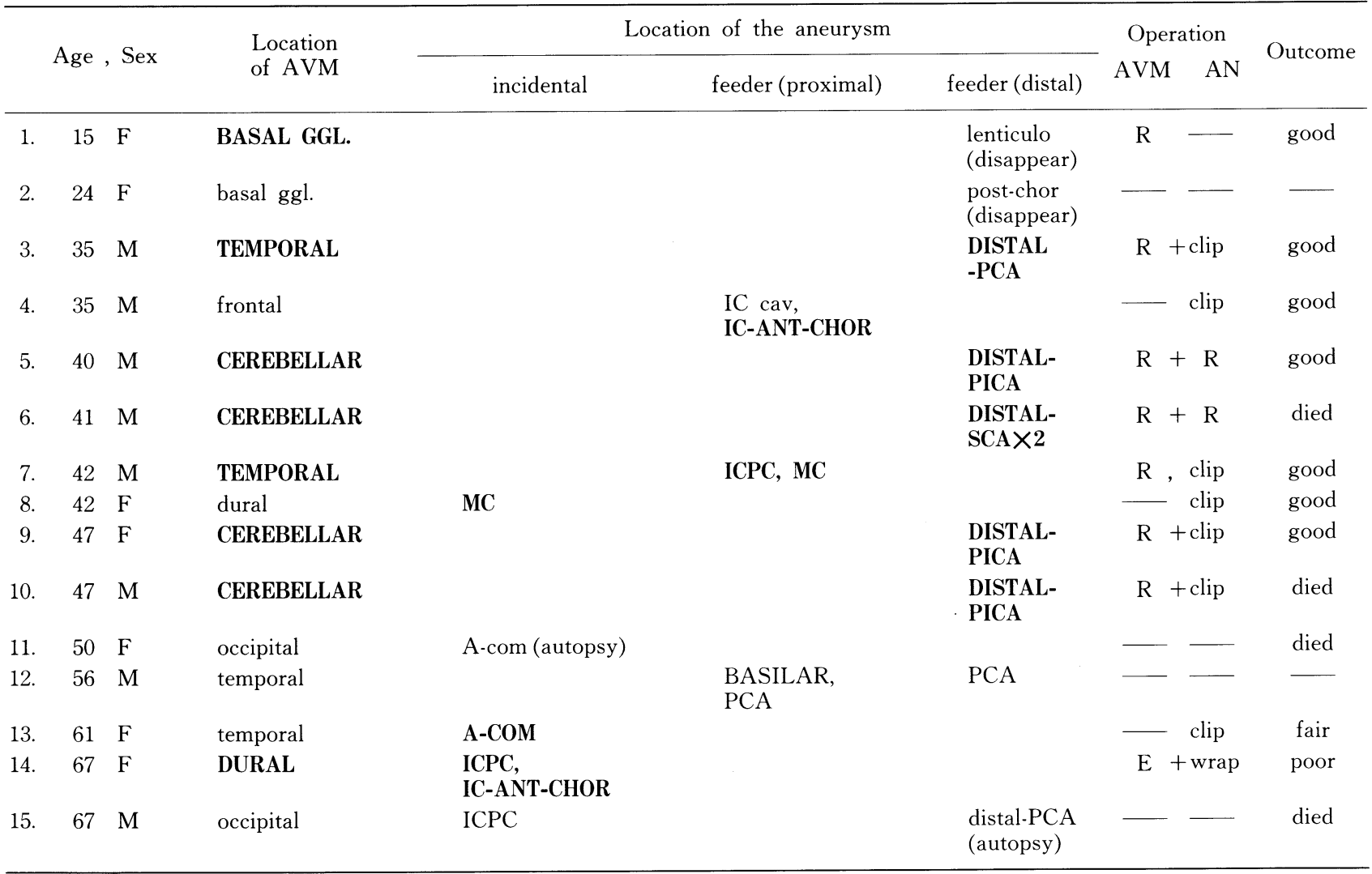

$\mathrm{R}$; removal $\mathrm{E}$; embolization + ; one staged surgery GOTHIC TYPE; operated lesions

\section{考察}

AVM と動脈瘤の合併を単なる偶然あるいは血管系の発 生異常の共存とする見方もあるが，この両者の合併に関す る報告が少なくない理由は, 動脈瘤の発生とAVM の病 態の因果関係が広く類推されているためであろう ${ }^{3)}$ 。すで に林ら ${ }^{4)}$ は彼らの経験した 3 例と文献例の reviewを行い， AVM に合併する動脈瘤の特徵として(1)77\%は feeder 上 に位置した。(2)前大脳動脈末梢，椎骨脳底動脈系に好発.

(3)通常みられない末梢部に好発. (4)AVM 摘出後自然消失 することがあると指摘し，動脈瘤発生にかかわる hemodynamic stress の重要性を証明するものとしている. われわれの症例については検討してみると前述の(1)～(4)が おおむねあてはまるのに加えて，(5)発症時の年齢が通常の AVM の好発年齢より高い，6短絡血流量をある程度反映 するとされる nidusの大きさが大きい場合に動脈瘤は feeder 上の特に末梢部に好発する傾向を示す，などが明ら かとなった．動脈瘤合併 AVM が非合併より高齢化して いた点であるが，高齢者ほど動脈瘤が多いというわけでは ないため，単純に hemodynamic stress が長期間及んだと することには無理があり，血管壁の加齢に伴う変化などほ
かに考慮すべき要素があるのであろう5). また末梢の動脈 瘤ほど hemodynamic tressをよく反映している点につい て，経過中短期間のあいたに自然消失した 2 例の若年 (AVM としては普通) 例では，動脈瘤が choroidal a. や lenticulostriate a.の末梢にみられた点は興味深い。これ らはモヤモヤ病でみられる pseudoaneurysm に酷似した動 脈瘤であり ${ }^{4)}$ ，高齟になって併発してきた動脈瘤とは異な る新たな subgroup としてとらえるべきものかもしれない.

AVM と動脈瘤合併例の治療方針を決定する場合の問題 を整理すると，冒頭に述べた(1)出血源の同定，(2)治療法と その順序，(3)非責任病巣に対する治療の 3 点が重要である.

AVM と動脈瘤はいずれも出血性脳血管障害を惹起する 代表的疾患であるが, 周知のごとくその natural history 特に再出血を起こす時期, 頻度には大きな相違があり, 治 療の第一歩はそのいずれが責任病巣であるかを決定するこ とにある。その際，病歴や神経症状，血管撮影所見から手 掛りを得るのは困難であり，注目すべきは CT 所見である. 従来から AVM と動脈瘤は『いわゆるクモ膜下出血』の 主たる原因疾患とされてきたが，この考え方はおそらく CT 出現以前の神経症候学に由来するものであり, 現在で は修正する必要に迫られている ${ }^{6)}$. すなわち，CT 上クモ 
膜下腔にのみ高吸収域を認めるものを primary SAH とし, 脳内出血や脳室出血が脳表のクモ膜下腔に及んだものを secondary SAH として区別すれば7) 8)，突発する頭痛や嘔 吐, 意識障害, 腰椎穿刺による血性髄液などは両者に共通 した所見である．解剖学的に，通常の動脈㽣はクモ膜下腔 に位置しているのに対し, AVM は nidusの一部が脳表や 脳室壁に露出していることが多くてもその大半は脳実質内 に埋っているため, 基本的な出血の広がりはおのずと前者 はクモ膜下腔に (primary SAH), 後者は脳内, 脳室内と なる.もちろん出血の程度によって動脈瘤からの出血でも $\mathrm{ICH}$ や IVH を伴うことは珍しくなく，またAVMで $\mathrm{SAH}$ を伴う場合 (secondary SAH) もありうる. 一義的出 血の部位に注目してCT 所見を検討し，原則として出血源 は，CT 上 SAH だけの場合は動脈瘤を，ICH や IVHを 伴う場合はAVMを疑って対応していくのが望ましい. 手術適応を検討する場合, AVM, 動脈瘤それぞれの局在, 大きさ, 神経症状, 伴う脳内血腫の大きさにより一概には いえないが，両者を同時に処置するのが望ましく，困難な 場合には，責任病巣から着手するのが原則である ${ }^{910)}$.動 脈瘤が責任病巣の場合は再出血の危険性が高い点に留意す ベきであり，われわれも入院後の再出血で 2 例失った経験 から通常の急性期手術と同様の対応が必要であったと痛感 した．動脈瘤が非責任病巣の場合，nidus 近傍の動脈瘤は AVM と同時に処置しうることもあれば，特にこの feeder 上の末梢に発生した動脈瘤は自然消失が経過中みられるこ ともあり，外科的に接近しにくい部位であればAVMの 手術適応に応じて follow-up することもある. しかし, 通 常の動脈瘤好発部に発生した動脈瘤はわれわれのシリーズ では出血の可能性が高かったため, AVMの手術適応にか かわらずこの動脈瘤の処置を行うべきであると思われた.

\section{結論}

1. AVM と動脈瘤合併例は非合併例より発症年齢が高 く，またAVMの nidus が大きい場合，動脈瘤は feeder
上の，特に末梢に好発する傾向がみられた。

2. 出血源は, CT上クモ膜下腔だけの場合は動脈瘤が, 脳内血腫や脳室内血腫を伴う場合はAVM が疑わしい.

3. 両者を同時に処置するのが望ましいが，困難な場合 には責任病巣から着手する。動脈瘤が責任病巣の場合は短 期間に再出血をおこしやすい.

4. 動脈瘤が非責任病巣の場合でも, 通常の動脈瘤好発 部に発生したものは出血の可能性が高いため処置すべきで あろう。

\section{文献}

1) Perret G, Nishioka H: Report on the cooperative study of intracranial aneurysms and subarachnoid hemorrhage. Section VI. Arteriovenous malformations. An analysis of 545 cases of cranio-cerebral arteriovenous malformations and fistulae to the cooperative study. J Neurosurg 25: 467-490, 1966

2) Spetzler RF, Martin NA: A proposed grading system for arteriovenous malformations. J Neurosurg 65: 476-483, 1986

3) Wilkins RH: Natural history of intracranial vascular malformations: A review. Neurosurgery 16: 421-430, 1985

4）林 靖二, 船橋利理, 板倉 徹, ほか: 脳動脈瘤発生に及 ぼす hemodynamic stress の重要性一脳動脈瘤, 脳動静脈奇 形合併例の分析一. Neurol Med Chir(Tokyo) 22:219-226, 1982

5) Ostergaard JR: Association of intracranial aneurysm and arteriovenous malformation in childhood. Neurosurgery 14: 358-362, 1984

6) Youmans JR: Neurological Surgery, WB Saunders Co, Philadelphia, 1982, pp 1653-1654

7) Aoki N: Subarachnoid hemorrhage and AVM (letter). Neurosurgery 18: 387, 1986

8) Takahashi S, Sonobe M, Shirane R, et al: Computer tomography of ruptured intracranial arteriovenous malformations in the acute stage. Acta Neurochir (When) 66: 87-94, 1982

9) Suzuki J, Onuma T: Intracreanial aneurysms associated with arteriovenous malformations. J Neurosurg 50: 742-746, 1979

10）鎌塚栄一郎, 知識鉄郎, 杉浦和朗 : 動脈瘤静脈奇形と動脈 瘤の 1 合併例, 両者に対する手術の優先順位について. Neurol Med Chir (Tokyo) 22:468-472, 1982 